\title{
Cholesterol Lowering Capability of some Lactobacillus Strains and its Effect on Mice Fed a High Cholesterol Diet
}

\author{
Mohamed Abd El Helim ${ }^{1}$, Shabaan Hashem ${ }^{2}$, Tamer Essam ${ }^{1}$ and Mohamed Omar ${ }^{1 *}$ \\ ${ }^{1}$ Microbiology Department, Cairo University, Egypt \\ ${ }^{2}$ Microbiology Department, Assiut University, Egypt
}

"Corresponding author: Mohamed Omar. Post Graduate Student in Microbiology Department, Microbiology Department, Faculty of pharmacy, Cairo University, Egypt, Tel: +0111 353 8882; E-mail: mohamedomar_asw@outlook.com

Received date: May 12, 2015, Accepted date: Jun 25, 2016, Published date: Jun 30, 2016

Copyright: @ 2016 El Helim MA, et al. This is an open-access article distributed under the terms of the Creative Commons Attribution License, which permits unrestricted use, distribution, and reproduction in any medium, provided the original author and source are credited.

\begin{abstract}
Elevated blood cholesterol is an important risk factor associated with Atherosclerosis and coronary heart disease. Several studies have reported a decrease in serum cholesterol during the consumption of large doses of fermented dairy products or Lactobacillus strains. Based on literature, in vitro cholesterol removal of lactic acid bacteria (LAB) has been accounted for their in vivo cholesterol reduction. But recently it has been proposed that such in vitro characteristic may not be directly relevant to their in vivo activity. The objective of this study was to find how much in vitro cholesterol reducing capability from bacterial culture media contain Lactobacillus reutri (ATCC 23272) and Lactobacillus casei (ATCC 393), As well as under vivo conditions. Bacteria used are a native strains isolated from a human and cheese origin respectively reflects its in vivo efficiency. Here, we investigate whether the given strains are capable of in vitro cholesterol assimilation or consumption using a colorimetric method. The proposed mechanism for this effect is the removal or assimilation of intestinal cholesterol by the bacteria, reducing cholesterol absorption. Although this effect was demonstrated in vitro, its relevance in vivo is still controversial. Furthermore, few studies have investigated the role of lactobacilli in atherogenesis Lactobacillus reutri (LA7) previously showed serum cholesterol reducing capability in mice subjected to fatty diet. Our in-vivo study was held as twenty male Swiss albino mice aged 4-6 weeks and weighing $25-30 \mathrm{~g}$ were orally ingested by $L$. casei and $L$. reutri. They were kept under a $12 \mathrm{hr}$ light/dark cycle at $22-26^{\circ} \mathrm{C}$ and a relative humidity of $50 \%$, in Cages $(15 \times 25 \mathrm{~cm})$, three mice used as a control group. Samples are taken in eppendorf tubes and tested for total serum cholesterol concentration. However, more clinical evidence is needed to strengthen these proposals.
\end{abstract}

Keywords Assimilation; Cholesterol; Lactobacillus casei; Lactobacillus reutri

\section{Introduction}

Cardiovascular disease is considered the principal global cause of morbidity and mortality by the World Health Organization, and therefore became a major scientific focus in both academic and industrial sectors. Atherosclerosis, an inflammatory disorder, is recognized as the essential cause of cardiovascular disease that accounts for approximately one-third of all deaths worldwide. Major advances in the understanding of atherosclerosis were made over the last decade and these discoveries provide insightful approaches that may help in the prevention of cardiovascular problems. Among the most important risk factors for atherosclerosis are high cholesterol, high blood pressure, and cigarette smoking [1]

People affected with hypercholesterolemia may avert the use of cholesterol-lowering drugs by practicing dietary control or supplementation of probiotics and/or prebiotics. Probiotics are defined as 'living microbial supplements that beneficially affect the host animals by improving its intestinal microbial balances. Prebiotics are 'indigestible fermented food substrates that selectively stimulate the growth, composition and activity of micro flora in gastrointestinal tract and thus improve hosts' health and well-being. When probiotics and prebiotics are used in combination, they are known as 'symbiotic'. The use of probiotics and prebiotics has only acquired scientific recognition in recent years although their applications as functional foods have been well-established throughout generations. In the interest of their promising effects on health and wellbeing, probiotics and prebiotics have become increasingly recognized as supplements for human consumption. In addition to improving gut health, probiotics have also been documented to exert other health promoting effects such as strengthening of the immune system, antihypertensive effects, prevention of cancer, antioxidative effects, reduction of dermatitis symptoms, facilitation of mineral absorption, amelioration of arthritis, and reduction of allergic symptoms and improvement of vulvovaginal candidiasis in women. Probiotics have also been studied for their Cholesterol-lowering effects [2].

\section{Aim of Work}

The objectives of this study are to determine whether $L$. casei, $L$. reutri would assimilate cholesterol and to confirm whether consumption of selected strains would significantly prevent an increase of serum cholesterol in mice fed a high-cholesterol diet.

\section{Materials and Methods}

\section{Source and maintenance of cultures}

Cultures of Lactobacillus casei (of cheese origin) and Lactobacillus reutri (of human origin) were obtained from Microbiological Resources Centre, Faculty of agriculture, Ain Shams University, (Cairo Mircn). 
Page 2 of 4

Cultures were maintained by sub culturing weekly with $1 \%$ inoculant in $10 \mathrm{ml}$ portions of sterile de man, Rogosa, Sharpe lactobacilli MRS broth (HI-Media Laboratories, Mumbai, India) and incubating for $18 \mathrm{~h}$ at $37^{\circ} \mathrm{C}$. Cultures were sub cultured twice in a like manner immediately before using. They were stored at $4^{\circ} \mathrm{C}$ between sub-cultures. Stock cultures were stored in $25 \%$ glycerol at $-20^{\circ} \mathrm{C}$ until use.

Each subculture was used for not more than five passages from the original culture to ensure the genetic stability of the micro-organisms.

\section{Measurement of cholesterol uptake}

Preliminary tests indicated that Lactobacillus acidophilus would during anaerobic growth, remove cholesterol from laboratory media.

Three different concentrations of standard cholesterol powder (50 $\mathrm{mg} / \mathrm{l}, 100 \mathrm{mg} / \mathrm{l}, 150 \mathrm{mg} / \mathrm{l}$ ) were prepared separately, added in a freshly prepared MRS broth, $10 \mathrm{ml}$ taken from each concentration in 10 sterile test tubes, respectively, autoclaved for $\left(20 \mathrm{~min}, 12^{\circ} \mathrm{C}\right)$, then $L$. casei, $L$. reutri was inoculated (1\%), each strain its optical density adjusted at 0.5 spectrophotometric ally at $600 \mathrm{~nm}$, in each test tube. The tube(s) was incubated an aerobically for $26 \mathrm{hr}$ at $37^{\circ} \mathrm{C}$ in a Gaspak hydrogencarbon dioxide anaerobic system. Samples taken from system each hour, cells were removed from the broth by ultra-centrifugation (Beckman, L77, ins) for $10 \mathrm{~min}$ at $12,000 \mathrm{X} \mathrm{G}$ and $1^{\circ} \mathrm{C}$. The cell pellet was re-suspended in a volume of distilled water equal to that of the original broth culture.

The o-phthalaldehyde method for measuring cholesterol described by Rudel and Morris [3] was used to determine the amount of cholesterol in the re-suspended cells and spent broth. Un-inoculated sterile broth was also analyzed in some experiments. Since some modifications with respect to sample volume and reagent volumes were used, the procedure is described here for convenience. The sample $(0.5 \mathrm{ml})$ was placed into a clean test tube (duplicates for each sample). Three milliliters of $95 \%$ ethanol was added to each tube, followed by $2 \mathrm{ml}$ of $50 \%$ potassium hydroxide. The contents of all tubes were mixed thoroughly after addition of each component. Tubes were heated for $10 \mathrm{~min}$ in a $60^{\circ} \mathrm{C}$ water bath, and after cooling, $5 \mathrm{ml}$ of hexane was dispensed into each tube. After mixing thoroughly with a vortex-Genie vibrator, on setting 5 for 20 seconds, $3 \mathrm{ml}$ of distilled water was added, and the mixing was repeated. Tubes were allowed to stand for $15 \mathrm{~min}$ at room temperature to permit phase separation. Then $2.5 \mathrm{ml}$ of the hexane layer was transferred into a clean test tube.

The hexane was evaporated from each tube at $600 \mathrm{C}$ under the flow of nitrogen gas. O-phthalaldehyde reagent $(4 \mathrm{ml})$ was added to each tube. The reagent contained $0.5 \mathrm{mg}$ of o-phthalaldehyde (Sigma Chemical Co., St. Louis, Mo) per $\mathrm{ml}$ of glacial acetic acid. The tubes were allowed to stand at room temperature for $10 \mathrm{~min}$, and then $2 \mathrm{ml}$ of concentrated sulfuric acid was pipette slowly down the inside of each tube. The contents of each tube were immediately mixed thoroughly on the vortex mixer as described previously. After standing at room temperature for an additional 10 minute, $A_{550}$ was read against a reagent blank. The $A_{550}$ was compared with a standard curve to determine the concentration of cholesterol. Results were expressed as micrograms of cholesterol per milliliter.

\section{In Vitro: determination of cholesterol uptake directly from human blood sample}

A freshly prepared MRS broth culture of L. casei, L. reutri (optical density 0.5 ) was inoculated (1\%) into $10 \mathrm{ml}$ of sterile MRS broth containing $1 \%$ of blood sample as the cholesterol source and incubated an aerobically for $25 \mathrm{hr}$ at $37^{\circ} \mathrm{C}$ in a gaspak hydrogen-carbon dioxide anaerobic system. samples taken from system each hour. , cells were removed from the broth by ultra-centrifugation (Beckman, L77, ins) for $10 \mathrm{~min}$ at $12,000 \mathrm{X} \mathrm{G}$ and $1{ }^{\circ} \mathrm{C}$. The cell pellet was re-suspended in a volume of distilled water equal to that of the original broth culture. The o-phthalaldehyde method for measuring cholesterol described by Rudel and Morris is held. As mentioned above in the first experiment.

\section{Animal model for In vivo evaluation of cholesterol reduction by lactic acid bacteria}

Administration of Lactobacillus reuteri CRL (104) cells/d) to mice for $7 \mathrm{~d}$ before inducing hypercholesterolemia, (by feeding mice with a fat-enriched diet for the subsequent $7 \mathrm{~d}$ ) was evaluated. At this low dose, $L$. reuteri was effective in preventing hypercholesterolemia in mice [4]. Twenty male Swiss albino mice aged 4-6 weeks and weighing 25-30 g were orally ingested by $L$. casei and $L$. reutri. They were kept under a $12 \mathrm{hr}$ light/dark cycle at $22-26^{\circ} \mathrm{C}$ and a relative humidity of $50 \%$, in cages $(15 \times 25 \mathrm{~cm})$, three mice used as a control group. Blood samples are taken in eppendorf tubes and tested for total cholesterol concentration at new kasr el ainy teaching hospital laboratory unit.

\section{Preparation of standard high cholesterol diet}

$1 \%$ of stabilized cholesterol powder added to solid commercial conventional diet.10 gm cholesterol powder weighted and added into mortar, 1-2 drops of tween 80 as emulsifier with gentle stirring then drop by drop hot water until form homogenous emulsion under water bath $60^{\circ} \mathrm{C}$, reaching final volume $50-40 \mathrm{ml}$ all this contend added directly on one kilo of solid commercial conventional diet.

\section{Results and Discussion}

Culture identification the identity of the cultures of lactobacilli used in this study was confirmed as $L$. acidophilus as described in the $8^{\text {th }}$ edition of Bergey's Manual of Determinative Bacteriology [5]. All strains were gram-positive, catalase-negative, non-spore forming rods and grew at $45^{\circ} \mathrm{C}$ but not at $15^{\circ} \mathrm{C}$. None produced ammonia from arginine, whereas all hydrolyzed esculin. All strains fermented cellobiose, galactose, glucose, lactose, maltose, and sucrose. None fermented mannitol, melezitose, rhamnose, sorbitol, and xylose. Fermentation of melibiose and raffinose was variable, as expected. The identity characteristics of all strains fit those of $L$. acidophilus more closely than any other species.

Total cholesterol: The different strains in isolated culture were placed in the presence of a known quantity of cholesterol $(100 \mathrm{mg} / \mathrm{l})$, and after incubation in variable time, the analysis of cholesterol after ultracentrifugation was realized by the colorimetric method.

Results from the screening of cultures for cholesterol uptake in vitro are shown in Table 1. To measure the cholesterol removed with the cells, pellet cells obtained by centrifugation was re-suspended in distilled water to original volume of the culture was calculated from the equation $\mathrm{A}=(\mathrm{B} / \mathrm{C})^{*} 100$ 
Citation: El Helim MA, Hashem S, Essam T, Omar M (2016) Cholesterol Lowering Capability of some Lactobacillus Strains and its Effect on Mice Fed a High Cholesterol Diet. Clin Microbiol 5: 253. doi:10.4172/2327-5073.1000253

Page 3 of 4

\section{Screening cultures for cholesterol uptake}

\begin{tabular}{|c|c|c|c|c|c|c|}
\hline \multicolumn{7}{|c|}{ Concentration for cholesterol in MRS broth spectrophotometrically } \\
\hline \multirow[b]{2}{*}{ Time } & \multicolumn{2}{|c|}{$50 \mathrm{mg} / \mathrm{liter}$} & \multicolumn{2}{|c|}{$100 \mathrm{mg} / \mathrm{liter}$} & \multicolumn{2}{|c|}{$150 \mathrm{mg} / \mathrm{liter}$} \\
\hline & L. casei & L. reutri & L. casei & L. reutri & L. casei & L. reutri \\
\hline 0 & 14.89 & 8.7 & 19.4 & 30.24 & 28.94 & 10.51 \\
\hline 1 & 22.19 & 20.8 & 6.4 & 33.25 & 27.5 & 0.136 \\
\hline 2 & 44.39 & 7.3 & 1.4 & 31.056 & 36.17 & 5.39 \\
\hline 3 & 47.4 & 5.8 & 33.5 & 35.77 & 28.455 & 36.95 \\
\hline 4 & 30.6 & 16.8 & 26.7 & 39.83 & 27.479 & 42 \\
\hline 22 & 58.6 & 39 & 29.8 & 5.6 & 3.821 & 3 \\
\hline 23 & 37.36 & 10.8 & 42.6 & 4.634 & 36.341 & 10.99 \\
\hline 24 & 79.23 & 61.4 & 47.6 & 18.13 & 11.3 & 84.42 \\
\hline 25 & 21.44 & 57.2 & 24.1 & 5.2 & 0.813 & 55.12 \\
\hline 26 & 16.39 & 27.2 & 66.4 & 8.617 & 29.18 & 20.42 \\
\hline
\end{tabular}

Table 1: Effect of cholesterol concentration on cholesterol uptake by $L$. casei and L. reutri

Where $\mathrm{A}=$ cholesterol remained with the pellet (as percentage), $\mathrm{B}=\mathrm{absorbance}$ of the sample containing the cells, $\mathrm{C}=\mathrm{absorbance}$ of the sample without cells (blank). It was observed that, sample containing no cells has no pellet and cholesterol was determined in the whole system.

\begin{tabular}{|l|l|l|}
\hline \multicolumn{3}{|l|}{ Concentration of cholesterol in 1\% blood sample + MRS broth } \\
\hline L. reutri & L. casei & Time (hr) \\
\hline 49.61 & 44.65 & 0 \\
\hline 56.11 & 63.65 & 1 \\
\hline 46.75 & 65.28 & 2 \\
\hline 51.38 & 71.58 & 3 \\
\hline 53.86 & 58.59 & 4 \\
\hline 54.77 & 51.38 & 5 \\
\hline 56.54 & 49.37 & 21 \\
\hline 60.41 & 52.57 & 22 \\
\hline 63.56 & 55.2 & 23 \\
\hline 48.85 & 60.45 & 24 \\
\hline 44.55 & 63.03 & 25 \\
\hline & & \\
\hline
\end{tabular}

Table 2: Effect of total cholesterol concentration on human blood sample by $L$. casei and $L$. reutri

Results from the Assimilation of cholesterol by L. casei, L. reutri during anaerobic growth in MRS broth contain-ing human blood sample are shown in Table 2.

\begin{tabular}{|l|l|l|l|l|l|}
\hline \multicolumn{2}{|l|}{$\begin{array}{l}\text { Oral ingestion of } \\
\text { reutri }\end{array}$} & \multicolumn{4}{|l|}{ Oral ingestion of $L$. casei } \\
\hline $\begin{array}{l}\text { MIC } \\
\text { E }\end{array}$ & $\begin{array}{l}\text { cholesterol } \\
\text { conc. mg/dl }\end{array}$ & $\begin{array}{l}\text { Mice } \\
\text { weight gm }\end{array}$ & $\begin{array}{l}\text { MIC } \\
\text { E }\end{array}$ & $\begin{array}{l}\text { Mice } \\
\text { weight gm }\end{array}$ & $\begin{array}{l}\text { cholesterol } \\
\text { conc. mg/dl }\end{array}$ \\
\hline 1 & 140 & 24 & 1 & 206 & 28.3 \\
\hline 2 & 139 & 31 & 2 & 197 & 31.6 \\
\hline 3 & 166 & 29 & 3 & 213 & 26 \\
\hline 4 & 150 & 30 & 4 & 182 & 23 \\
\hline 5 & 118 & 32 & 5 & 237 & 22 \\
\hline 6 & 126 & 29 & 6 & 155 & 35 \\
\hline 7 & 171 & 20 & 7 & 208 & 28.6 \\
\hline 8 & 73 & 29 & 8 & 136 & 35 \\
\hline 9 & 190 & 25 & 9 & 188 & 33.5 \\
\hline 10 & 153 & 25.5 & 10 & 71 & 27 \\
\hline
\end{tabular}

Table 3: Effect of and L. reutri on the prevention of hypercholesterolemia in mice

Influence of feeding L. casei, L. reutri on serum cholesterol levels in mice on high cholesterol diet, is summarized in Table 3.

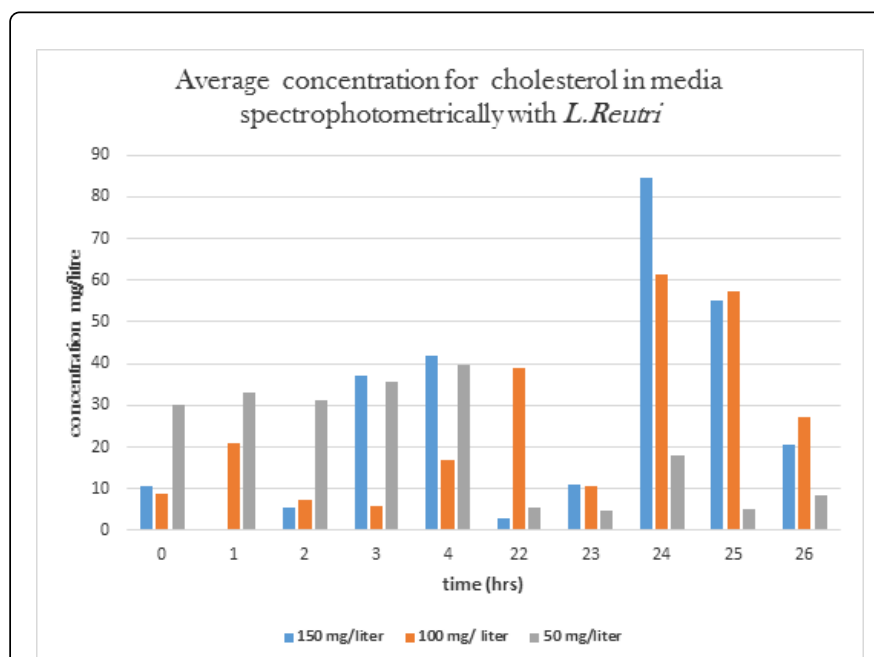

Figure 1: Average cholesterol removal from MRS media by Lactobacillus reutri

Results from the screening of cultures for cholesterol uptake are shown in Table 1. Cholesterol concentrations in the cell suspensions ranged from $50 \mathrm{mg} / \mathrm{liter}$ to $150 \mathrm{mg} /$ liter for both strains. After calculation we observed that Lactobacillus reutri had more cholesterol removal ability than Lactobacillus casei shown in Figures 1-4. 
Page 4 of 4

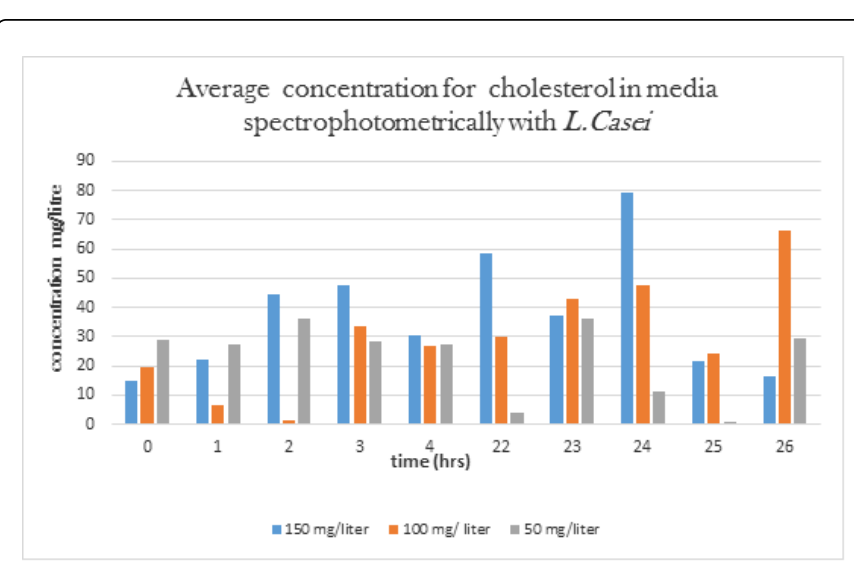

Figure 2: Average Cholesterol removal from MRS media by L. casei.

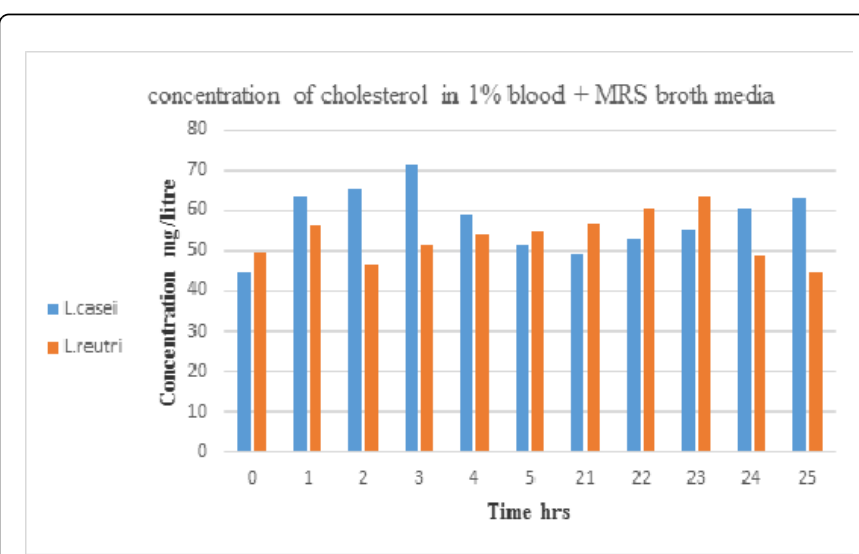

Figure 3: represent cholesterol concentration for L. reutri, L. casei into $1 \%$ direct Blood Sample

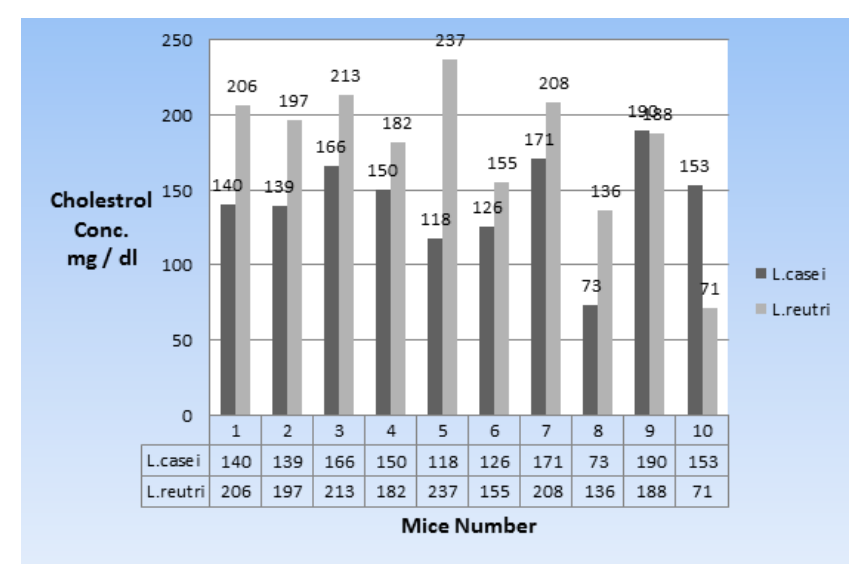

Figure 4: In vivo effect of L .reutri, L. casei on Mice cholesterol level (Influence of feeding)

\section{Conclusion}

A high level of serum cholesterol in humans is generally considered to be a risk factor for coronary heart disease [6]. Much interest now exists to find ways to decrease the levels of serum cholesterol. Some reports have suggested the possibility of decreasing the serum cholesterol levels after ingestion of L. acidophilus [7-9], the mechanism by which the in vivo serum cholesterol level was lowered after pigs were fed with $L$. acidophilus was explained by a direct action of $L$. acidophilus on cholesterol which was found under in vitro conditions. L. reutri, L. casei and other lactic acid bacteria have been used as probiotics in various products. This study shows the potential of using $L$. reutri and $L$. casei as an adjunct to reduce serum cholesterol levels. Further in vivo study is necessary to prove the hypo-cholesteremic effect of these Lactobacillus reutri and L. casei strains in humans. Lactic acid bacteria including 1 . reutri are frequently associated with probiotics effects in humans [10].

\section{Acknowledgements}

An appreciation is expressed to biotechnology center faculty of pharmacy, Cairo University. BTC (FOPCU).

\section{References}

1. Mizuno Y, Jacob RF, Mason RP (2011) Inflammation and the development of atherosclerosis. J Atheroscler Thromb 18: 351-358.

2. Ooi LG, Liong MT (2010) Cholesterol-lowering effects of probiotics and prebiotics: a review of in vivo and in vitro findings. Int J Mol Sci 11: 2499-2522.

3. Rudel LL, Morris MD (1973) Determination of cholesterol using ophthalaldehyde. J Lipid Res 14: 364-366.

4. Taranto MP, Medici M, Perdigon G, Ruiz Holgado AP, Valdez GF (2000) Effect of Lactobacillus reuteri on the prevention of hypercholesterolemia in mice. J Dairy Sci 83: 401-403.

5. Buchanan RE, Gibbons NE (1974) Bergey's manual of determinative bacteriology. (Eighth edition.) Baltimore: Williams \& Wilkins Co.

6. Pekkanen J, Linn S, Heiss G, Suchindran CM, Leon A, et al. (1990) Tenyear mortality from cardiovascular disease in relation to cholesterol level among men with and without preexisting cardiovascular disease. N Engl J Med 322: 1700-1707.

7. Gilliland SE, Nelson CR, Maxwell C (1985) Assimilation of cholesterol by Lactobacillus acidophilus. Appl Environ Microbiol 49: 377-381.

8. Gilliland SE (1989) Hypocholesteremic action of lactobacilli. NIZO (p. 77-88.) In Proceedings of the NIZO-Workshop Fermented Milks and Health. Ede, the Netherlands.

9. Gilliland SE (1990) Health and nutritional benefits from lactic acid bacteria. FEMS Microbiol Rev 7: 175-188.

10. Lin MY (1995) The beneficial effects of lactic acid bacteria on human health. J. Chin Nutr Soc 20: 367-380. 